\title{
U.S. ROBOTS AND THEIR IMPACTS IN THE TROPICS: EVIDENCE FROM COLOMBIAN LABOR MARKETS
}

\author{
Adriana D. Kugler \\ Maurice Kugler \\ Laura Ripani \\ Rodimiro Rodrigo \\ Working Paper 28034 \\ http://www.nber.org/papers/w28034 \\ NATIONAL BUREAU OF ECONOMIC RESEARCH \\ 1050 Massachusetts Avenue \\ Cambridge, MA 02138 \\ October 2020
}

We are grateful to the Inter-American Development Bank for research support. We thank George Akerlof, David Dorn, Laura Schechter, Luis Baldomero-Quintana and participants at the LACEA conferences in Ecuador and Mexico and seminar participants at the Inter-American Development Bank for comments. The views expressed herein are those of the authors and do not necessarily reflect the views of the National Bureau of Economic Research.

NBER working papers are circulated for discussion and comment purposes. They have not been peer-reviewed or been subject to the review by the NBER Board of Directors that accompanies official NBER publications.

(C) 2020 by Adriana D. Kugler, Maurice Kugler, Laura Ripani, and Rodimiro Rodrigo. All rights reserved. Short sections of text, not to exceed two paragraphs, may be quoted without explicit permission provided that full credit, including $\odot$ notice, is given to the source. 
U.S. Robots and their Impacts in the Tropics: Evidence from Colombian Labor Markets

Adriana D. Kugler, Maurice Kugler, Laura Ripani, and Rodimiro Rodrigo

NBER Working Paper No. 28034

October 2020

JEL No. C33,C36,F66,J21,J23,J63

\begin{abstract}
Previous studies for developed countries show negative short-run impacts of automation on employment and earnings. In this paper, we instead examine whether automation by a key trading partner can hurt workers in a developing country. We specifically focus in Colombia's labor market, and how the automation in the U.S. impacts Colombian workers by replacing exports from Colombia for cheaper robot-made U.S. products. We use employer-employee matched data from the Colombian social security records combined with data on U.S. exposure to robots in different sectors from 2011 to 2016 to examine if robots in the U.S. are displacing workers in Colombia. We find that U.S. robots decrease employment and earnings for Colombian workers in those sectors of local labor markets that have high levels of automation -measured as robots per thousand workers- in the U.S. labor market. In terms of turnover, as expected, there is an increase in dismissals and a decrease in hires for workers in sectors highly impacted by robots in the U.S. Moreover, the negative displacement effects of robots are greater for women; older workers; workers employed in small and medium sized enterprises, and workers employed in manufacturing. Importantly, local labor markets which exported the most to the U.S. in the past, are also the most affected by the increased adoption of U.S. robots, suggesting that Colombian workers may be losing employment to automated jobs reshored back to the U.S. Our estimates suggest that during our period of analysis, the adoption of robots in the U.S. led to a cumulative loss of between 63,000 and 100,000 jobs in Colombia.
\end{abstract}

Adriana D. Kugler

Georgetown University

McCourt School of Public Policy

37th and O Streets NW, Suite 311

Washington, DC 20057

and NBER

ak659@georgetown.edu

Maurice Kugler

George Mason University

Schar School of Policy and Government

3351 Fairfax Drive, MS 3B1

Arlington, VA 22201

mkugler@gmu.edu
Laura Ripani

Inter-American Development Bank

1300 New York Avenue N.W.

Washington, DC 20577

laurari@iadb.org

Rodimiro Rodrigo

Georgetown University

Department of Economics

37th and O Streets, NW

Washington, DC 20057

rr1041@georgetown.edu 


\section{Introduction}

Automation has had a transformational impact on labor markets both in the U.S and in Europe.

Evidence for advanced economies suggests that automation has contributed to falling employment and earnings in the short run, especially for the least educated. For developing economies, it is still unclear what will be the extent of the impact of automation on workers. Several factors could moderate the effect of automation in developing economies, including the lower cost of labor relative to capital and the slower introduction of technology in these economies. Moreover, the negative direct effects of domestic automation on employment and wages in the short run could be offset by the positive long-run reinstatement effect due to productivity increases from robotization. ${ }^{1}$ In addition, developing countries, highly connected to developed trade partners experiencing largescale robotization, are also likely to face the negative impacts of robotization abroad on employment and wages.

In this paper, we explore the link between robotization in the U.S. and labor market outcomes in Colombia. We use data from the International Federation of Robotics (IFR) to measure automation in the U.S. and microdata from the Colombian Social Security records to examine the impact on formal labor market outcomes including employment, wages, dismissals and hires. We assign higher exposure to robotization in a local labor market on a given sector to those locations with larger employment shares in sectors highly exposed to robots in the U.S. Our identification strategy, thus, relies on sectoral variation in robotization across labor markets in robots and assumes that the only reason why labor market behavior varies in finely defined labor markets across sectors over time is due to robotization and not due to any other factors. Since the Colombian Social Security records

\footnotetext{
${ }^{1}$ Autor and Salomons (2018) and Acemoglu and Restrepo (2018 and 2019) consider these displacement and reinstatement effects within general equilibrium frameworks that include labor-saving robot use, skill-biased technology adoption, sectoral reallocation (of both output and labor) and shifts in relative prices.
} 
include information on the sector in the previous and current job as well as information on whether and when the person has moved in the past, we can assign exposure to robotization to all formal workers. Moreover, since we use microdata, we can also control for all other socio-demographic and economic factors that can affect labor market outcomes such as age, gender, and firm size, while including high-dimensional fixed-effects for industry, local labor market, year and quarter.

Within Latin America and the Caribbean, Colombia presents an interesting case to study the impact of U.S. robots because Colombia is a country that is still in the very early stages of the adoption of robots for production purposes. Even as the adoption of robots grew five-fold in Colombia from 2011 to 2016, by 2016 there were only 124 robots in total in the country. Because of that, we do not need to account for the impacts of domestic robots on local labor markets in our analysis. In addition, the U.S. is Colombia's largest trading partner, with more than $30 \%$ of Colombian total exports going to the U.S. from 2011 to 2016, and about the same proportion of aggregate Colombian imports arriving from the U.S. We are, thus, interested in whether Colombian workers are indeed affected by automation in the U.S., and if so, which workers are most impacted by U.S. automation in Colombia, and how this may affect employment and income inequality, through wages.

Anecdotal evidence suggests that the mechanism through which U.S. robots compete with Colombian workers is the trade channel, in particular through reshoring. According to Reshoring Initiative, ${ }^{2}$ in 2016 Group Phoenix, a multinational company in the food and beverage packaging industry (one of the top industries in terms of robot adoption in the U.S.), engaged in substantial reshoring of production from Colombia to the United States. This reshoring initiative involved an investment of 48.7 million to expand their subsidiary Phoenix Packing Operations, in Pulaski

\footnotetext{
${ }^{2}$ Reshoring Intiative is an NGO that assists U.S. companies in their efforts to shift from offshoring to cheaper local production in the U.S.
} 
County in Virginia, which brought 145 jobs back to the U.S. from Colombia. ${ }^{3}$ Thus, these jobs coming back to the U.S. due to reshoring driven by automation would somewhat (though not fully) mitigate the displacement effects of automation in the U.S. estimated by Acemoglu and Restrepo (2020).

Our main findings, indeed, show negative impacts of U.S. robotization on the employment and wages of Colombian workers, which may be driven by the reshoring mechanism illustrated by the Group Phoenix example above. Our results imply one more robot in the U.S. reduces formal Colombian employment by about 1.2 to 1.4 workers, and slightly less than a full worker per our IV estimate. During 2011 to 2016, our period of analysis, these results suggest that the known adoption of 70,000 new robots in the U.S. would lead to a cumulative loss of between 63,000 and 100,000 jobs in Colombia. Also, consistent with displacement of Colombian workers by U.S. robots, we find greater dismissals and reduced hiring of Colombian workers in sectors and local labor markets more highly exposed to robots in the U.S. We also analyze differential effects by gender, age groups, firm size and sector of employment. We find greater displacement by U.S. robots on women, older and middle-aged workers, and workers employed by small and medium-size enterprises (SMEs). Perhaps not surprisingly, we find bigger effects in the manufacturing sector and, in particular, in the automotive, electronic, and food and beverages sectors. The greater effects on women, older workers and those employed in SME's suggest that the most vulnerable formal workers are affected most adversely from U.S. robot exposure. Thus, U.S. robotization may well be exacerbating income inequality in Colombia. Interestingly, these negative effects are attenuated as the proportion of workers in the informal sector on a local labor market gets larger, suggesting

\footnotetext{
${ }^{3}$ While the governor of Virginia attributed the success of this reshoring initiative to the development of an advanced-manufacturing hub in Pulasky County, it is also the case that the plastics sector in which this company operated is among the top five industries in terms of robot adoption in the U.S.
} 
that informality may work as a shock absorber to the additional competition from robots faced by Colombian workers.

We further examine if the impacts of U.S. robots on Colombian employees work through a trade channel. Presumably, if U.S. producers now have access to lower cost production at home due to the use of more efficient robots, they may now find it cheaper to produce certain goods in the U.S., which they used to import from countries producing with cheaper labor. ${ }^{4}$ We examine if, indeed, Colombian jobs may be lost to reshoring of production back to the U.S. now that robots are available to American companies by looking at whether the impacts are greater in local labor markets with a high-level of pre-existing exports. Our models interacting U.S. robot exposure with pre-existing exports in the local labor market, show indeed greater negative impacts of U.S. robot exposure on employment, wages and dismissals in higher export localities. ${ }^{5}$ This evidence suggests that the displacement effect we observe in Colombia may be due to global value chain (GVC) repositioning, with component production by multinational corporations (MNC) increasingly shifting back to headquarters, or due to reduced demand of final products from Colombia which are now being produced by robots in the U.S.

Our paper contributes to the existing literature on automation in a number of ways. First, we use microdata to examine not only the impacts of robots on formal employment and wages, but also to examine the dynamics of job flows. Second, we consider the distributional impacts of automation on labor markets in a developing country. Third, we explore the effects of automation across borders through trade and add to the evidence on the link between automation and reshoring.

In Section 2, we review the literature on the impact of automation on employment and wages.

\footnotetext{
${ }^{4}$ Even if U.S. production with robots is somewhat costlier than the production of Colombian exports, it may be optimal to reshore and produce closer to U.S. assembly lines and consumers to reduce transportation costs.

${ }^{5}$ This is consistent with Eaton et al. (2008), who document that Colombian exporters locked out by reshoring retrench to relatively less lucrative markets until they are able to open their markets in the U.S. again.
} 
In Section 3, we explain our identification strategy. In Section 4, we describe in detail the IFR data, the administrative social security records and the trade data that we use for our analysis. In Section 5, we present our empirical findings on the effects of exposure to robots on employment, wages and turnover, including heterogeneous effects and the role of pre-existing export orientation in magnifying these effects. We conclude in Section 6.

\section{Literature Review}

This paper contributes mainly to three strands of the literature. First, we add to the nascent literature on the impact of automation on labor markets in developing economies, since much of the evidence has focused on developed countries. Second, our paper builds on the literature about automation and reshoring with very granular labor and trade data. Third, we contribute to the literature examining the distributional impacts of automation.

Much of the recent research on the impact of automation on employment and wages focuses on developed countries. Acemoglu and Restrepo (2020) found that, from 1990 to 2007, the penetration of industrial robots in the U.S. as measured by the IFR reduced both employment and wages. Their results imply that the robots generated a loss of about 400,000 jobs. Many of these job losses were middle-income manufacturing jobs, especially in the automotive, plastics, and pharmaceuticals sectors. Also, for the U.S., Dinlersoz and Wolf (2018) use the U.S. Census Bureau's Survey of Manufacturing Technology to provide new evidence on the plant-level relationship between automation, labor and capital usage, and productivity. They find that more automated establishments have lower labor shares and higher capital shares. These establishments also show a smaller fraction of production workers being paid higher wages; higher labor productivity; and larger long-term labor share declines. Acemoglu, LeLarge and Restrepo (2020) use French manufacturing plant-level panel 
data and find that greater robot-use reduces the labor share, the fraction of production workers in employment and increases value added.

Graetz and Michaels (2018) implemented a broader analysis for developed countries. They use international and inter-industry variation in robot penetration to gauge the effect of robotization on labor markets in 17 countries including Australia, South Korea, U.S. and fourteen European countries. They find overall positive effects on productivity and wages; no significant reduction in total employment; and a negative effect on the employment share of less-skilled workers.

A recent literature on automation and reshoring shows a decline in relocation activities by advanced economies and a reduction in employment in emerging economies. Less than $20 \%$ of internationally traded goods are labor intensive and this number has declined sharply over the past decade. GVCs are, instead, becoming more knowledge-intensive and dependent on highly qualified workers. Krenz et al. (2018), analyze 43 countries and nine manufacturing sectors, and provide evidence that an increase by one robot per thousand workers is associated with a $3.5 \%$ increase of reshoring activity. Moreover, the authors find that the adoption of robots leads to reshoring benefitting high-skilled workers, but not low-skilled ones, from advanced economies. Kinkel et al. (2016), study data for 3,313 manufacturing firms across seven European countries, finding that firms using industrial robots in their production processes are less likely to offshore production activities outside Europe. ${ }^{6}$ Artuc et al. (2018) also use cross-country data and find ambiguous labor market effects. They find that higher own-robot intensity at the country-industry level is associated with higher imports from developing countries within the industry, but even stronger increase in exports to those countries. Finally, Hallward-Driemeier and Nayyar (2019) show that higher intensity in the use of robots in high-income countries has a positive impact on FDI growth

\footnotetext{
${ }^{6}$ Khandelwal (2010) also shows that competition from low-wage markets has smaller adverse effects on employment and output in sectors with long quality-ladders in developed countries.
} 
from high to low- and middle-income countries during the 2000s. Our paper examines whether U.S. automation is associated with job losses in a developing country. Moreover, we examine if these association is greatest in those sectors with greater pre-existing export orientation towards the U.S. The papers closest to ours are two papers focusing on the effect of U.S. robots on Mexico's local labor markets. First, Faber (2020) uses aggregate formal employment from local labor markets in Mexico between 1990 and 2015 and finds that robots in the U.S. have negative impacts on exports and employment in Mexico. Second, Artuc, et al. (2019) find that a rise of one robot per thousand workers in the U.S. lowers export growth per worker from Mexico to the U.S. by 6.7 percent. They also find that robotization in the U.S. induced a reduction in aggregate formal employment in local labor markets where occupations were more susceptible to being automated, but increased manufacturing employment elsewhere. In contrast to Faber (2020) and Artuc et al. (2019), our paper uses microdata from social security records so that our measures of formal employment are more precise. In addition, we can access formal individual-level real wages over time. Therefore, we analyze the impacts of automation abroad on individual-level employment and wages as well as dismissals and hires. Neither Faber (2020) nor Artuc et al. (2019) provide evidence of how U.S. robotization impacts the wages of Mexican workers. This evidence is crucial to make the case that U.S. robotization induces a displacement effect on Latin American workers - Mexican in their case and Colombian in ours. We document the negative impact on Colombian formal wages, especially in sectors in which U.S. robot intensity has increased most and in which Colombian export orientation used to be highest. Moreover, we look at heterogeneous effects on characteristics unexplored in the studies focusing on the Mexican case, including age and firm size. Unlike these studies, our paper has the advantage that, given the low robot adoption in Colombia, we do not have to separately identify the impacts of domestic and foreign automation. Finally, instead of analyzing local labor 
markets aggregate employment, our paper exploits matched employer-employee data. We, thus, use more granular data which allows us to control for compositional effects and to analyze for the first-time labor transitions, i.e., hirings and separations.

While much research has been focused on the U.S. and Europe, there is limited evidence about the effects of this new wave of automation on workers in Latin America and the Caribbean (LAC). Our paper aims to close this gap in the literature. Although $35 \%$ of exports in LAC are resourcebased and $15 \%$ are low technology exports, another $30 \%$ are medium and $20 \%$ high technology manufacturing exports, respectively (Cardenas and Kugler, 2011). This means that there is scope in the region for routinized key labor tasks to be performed by robots. While there are currently very few industrial robots in LAC as a share of the global stock, there is already some evidence of technology adoption in the region. For example, Molina (2020) reports technology and quality upgrading in Colombian manufacturing in response to Chinese import penetration. Similarly, Amiti and Khandelwal (2013) have shown that exposure to competition through lower tariffs induces quality upgrading for producers close to the global frontier and Kugler and Verhoogen $(2009,2012)$ show more skill and quality upgrading for Colombian importers and exporters respectively. Adoption of new technologies and upgrading could offset the reshoring and to extent the displacement effect from U.S. robotization that we find. A separate literature also indicating a possible link between trade and increased productivity in developing countries, Eslava et al. (2013) for Colombia and Topalova and Khandelwal (2011) for India show that increased trade liberalization can induce productivity enhancing reallocation within developing countries either because of international competition or access to more technologically advanced imports. In the short run, however, automatization in developed countries can generate reshoring. This is the focus in our paper. 


\section{Empirical Strategy}

The empirical approach consists of estimating the impact of exposure to robots on employment, wages and workers' turnover. Our identification strategy consists of exploiting the sectoral and geographical variation in exposure to U.S. robots given past sectoral composition in each local labor market. Given that this exposure to U.S. robots is pre-determined prior to current local labor market conditions, we are able to estimate the causal impact of exposure to U.S. robots on individual employment, wages and turnover outcomes.

We measure exposure to U.S. robots by doing analysis at the local labor market level using the definition of the OECD for Functional Urban Areas. We use the classification generated by Sanchez-Serra (2016) for Colombia to define these local labor markets or economic units, which are characterized by densely inhabited "city centers" and surrounding "commuting zones". We then define exposure to robots within local labor markets at in the 19 production sectors compiled by Acemoglu and Restrepo (2020) with data from the IFR described in the next section. We construct a Bartik-type measure of exposure to U.S. robots in Colombian local labor markets. For that, we assume that local labor markets in Colombia are differentially affected by the increase of U.S. robot adoption across sectors/industries. In particular, we use the robots per thousand workers for industry $\mathrm{j}$ in the U.S. and weight that by the share of employment in industry $\mathrm{j}$ in Colombia's local labor market c. Thus, our measure of exposure to the U.S. robots is:

$$
\text { ExposuretoRobots }_{j c t}=l_{j c 2008}^{C O L} \times\left(\frac{\operatorname{Robots}_{j t}^{U S}}{\operatorname{Labor}_{j 2008}^{U S} / 1000}\right)
$$

We use lagged weights $l_{j c 2008}^{C O L}$ to mitigate endogeneity concerns due to mechanical correlation

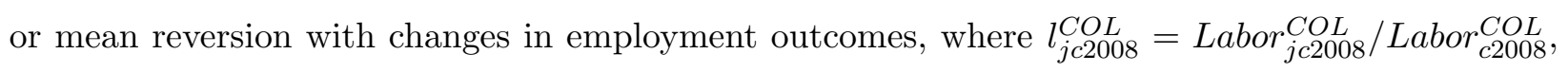


where exposure to robots and outcomes are measured between 2011-2016.

We then estimate a regression of individual level employment, wages, hires and separations on the exposure-to-robots variable, as well as individual level characteristics, local labor market, sector, year and quarter fixed effects, as follows:

$$
y_{i j c t q}=\alpha+\rho \text { ExposuretoRobots } s_{j c t}+\beta X_{i j c t q}+\theta_{j}+\pi_{c}+v_{t}+w_{q}+\epsilon_{i j c t q}
$$

where the dependent variable will be the probability of employment, $\operatorname{Pr}\left(E_{i j c t q}\right)$, wages, $W_{i j c t q}$, the probability of being hired conditional on not having been employed the previous quarter, $\operatorname{Pr}\left(H_{i j c t q}\right)$ and the probability of being separated from the job, $\operatorname{Pr}\left(S_{i j c t q}\right)$ for worker $i$ in sector $j$ in local labor market $c$ in year $t$ and quarter $q . X_{i j c t q}$ controls for individual characteristics including a female dummy, age group dummies (for 25-34, 35-54 and more than 55 year old groups, where the under 25 group is our benchmark), and firm size dummies for small (less than 50 employees), medium (50-250) firms (where large firms with more than 250 employees are our benchmark). We cluster standard errors at the state level to allow for autocorrelation within labor markets over time.

As robustness tests, we estimate regression (2) also controlling for imports from China and excluding the automotive sector. We also examine models with interactions of the exposure to robots measure with the female dummy, the different age groups and the different firm sizes to see if the effects of automation are heterogenous for different types of workers. In addition, we examine models with sector interactions to examine which sectors face the greatest impacts from exposure to robots.

The identification of equation (2) could suffer from two main threats (a) possible measurement 
error of the exposure to U.S. robots variable, mainly due to the assumptions applied to distribute the unclassified robots across industries, discussed in Section 4.2; and (b) the presence of a global shock differentially affecting industries in the same way as robots. One such shock having sector-specific impacts is the 2008 financial crisis, which had larger effects on industries with higher dependence on external finance. Those industries or Colombian regions highly specialized on those industries, could have become less competitive, reducing their exports and local employment, regardless of their adoption of robots in the U.S. ${ }^{7}$ To distinguish our channel from other such shocks and identify the impacts of U.S. industries' adoption of robots, we instrument the U.S. exposure to robots by an analogous measure constructed using the industries' adoption in European countries ${ }^{8}$ as follows:

$$
\text { ExposuretoRobots }{ }_{j c t}^{E U R O}=l_{j c 2008}^{C O L} \times \frac{1}{N_{z}} \sum_{z}\left(\frac{\text { Robots }_{j t}^{z}}{\text { Labor }_{j 2008}^{z} / 1000}\right)
$$

We then examine the trade mechanism, i.e. if the impact of exposure to U.S. robots is greater for sectors in local labor markets that had strong pre-existing trade ties with the United States, we estimate models with interactions with previous exports to the U.S. and previous imports from the U.S. as follows:

$$
\begin{aligned}
y_{i j c t q} & =\alpha+\rho_{0} \text { ExposuretoRobots }_{j c t} \\
& +\rho_{1} \text { ExposuretoRobots }_{j c t} \times U S \text { Export }_{c t}+\rho_{2} \text { ExposuretoRobot }_{j c t} \times \text { USImport }_{c t} \\
& \quad+\phi U S \text { Export }_{c t}+\lambda \text { ISImport }_{c t}+\beta X_{i j c t q}+\theta_{j}+\pi_{c}+v_{t}+w_{q}+\epsilon_{i j c t q}
\end{aligned}
$$

\footnotetext{
${ }^{7}$ We do not believe reverse causality is an important concern in our context, given that U.S. imports (exports) from (to) Colombia, represents less than $0.45 \%$ (0.9\%) of U.S. total imports (exports). Nonetheless, in Section 5.3. we use instrumental variables approach as a robustness check to eliminate this potential bias.

${ }^{8}$ We include robots from five representative European countries, i.e. $N_{z}=5$ and $z \in\{$ Netherlands, France, Spain, Sweden and the U.K. $\}$ as detailed in Section 5.3
} 
where U.S. exports and U.S. imports are the three-year lags of exports and imports to and from the U.S. in local labor market $c$ relative to its gross domestic product. A negative coefficient on the interaction term with exports would indicate that those local labor markets that previously exported more to the U.S. experience more adverse effects from exposure to robots. This would likely be the case, if certain sectors in these regions are losing jobs because U.S. producers are reshoring - now making goods domestically that they used to import from Colombia. Specification (3), thus, allows us to test for the possibility of reshoring back to the U.S. due to access to lower cost and more efficient robots. By contrast, if there were more imports from the U.S. in the past, it is not clear that it will be cheaper for firms in these sectors to import from the U.S. and what implications this may have in terms of employment and wages.

\section{Data Description}

\subsection{Colombian Social Security Administrative Records (PILA)}

We use administrative data from the Colombian Social Security records for our analysis. The social security records are compiled in the Planilla Integrada de Liquidación de Aportes (PILA), the data that comprises all the payroll contributions made by formal workers in Colombia. These data include the contributors' reported information for each of the funds to which they are required to contribute, which could include health contributions or pension contributions. The contributor, which is typically the employer or the individual if the person is self-employed and contributing to the system, has to provide this information so that the contributions are paid by the Social Security System to its employees. The PILA observations are not recorded at fixed intervals, since the data come from administrative records of the contributions made by workers to their respective health 
and pension plans, at different dates - which are not predetermined- throughout the year. ${ }^{9}$ We construct a monthly income measure by aggregating the base income reported for each employee on a monthly basis. The total monthly income was converted to Colombian pesos of December 2011 using the monthly inflation rate for each state in Colombia (called Departments). For this study, we analyze individual employment status and labor income at the end of each quarter from 2011 through 2016, with more than 226 million registries, reflecting the tracking of about 9 million workers per quarter over six years. ${ }^{10}$

We classify workers who have made at least one contribution in a particular month as being formally employed for that month. Since the PILA is a census of the formal labor force only, we thus, generate formal employment indicators that take the value of one for anyone who has a payment report and a value of zero for anyone who does not. For workers who cannot be found at a given time in the social security roster, we are unable to say if the worker is unemployed, out of the labor force, or informally employed. Therefore, our analysis to identify the probability of hiring or separating from a job, only considers transitions from non-formal-employment to formal employment or from formal employment to non-formal-employment. We estimate transitions from non-formalemployment to formal or registered employment as those in which an individual was not in the system the previous quarter and, then, appears as contributing into the pension system the next month. ${ }^{11}$ Similarly, we estimate transitions from formal employment to non-formal-employment

\footnotetext{
${ }^{9}$ This means that the database may record for more than one monthly payment to the same fund for the same person and that the number of days quoted in a month can be greater than the duration of the month.

${ }^{10}$ The PILA information used in this study contains data for the formal labor market in Colombia. A major advantage of using Social Security data is that individuals can be followed over time. A disadvantage of the PILA is that it does not cover the formal sector. The alternative to using the PILA would be to use repeated cross-sections of household surveys, but we would not be able to do analyses of transitions. In addition, we believe the adoption of robots in the U.S. are most likely to affect formal sector firms. To examine weather the size of the informal sector affects our results, we do use data on informality at the LLM level to understand if our automation effects are exacerbated or reduced when the informal sector is larger.

${ }^{11}$ The results of contributions to the health and pension funds are very similar, but there is a possibility of registering payments to the health scheme without working. For this reason, we rely only on registries into the pension system.
} 
as those in which an individual was in the system the previous quarter and, then, appears as not contributing into the pension system the next quarter.

The PILA database reports information on worker gender and age. We construct a dummy variable for female and three dummy variables for age groups $(<25$ years of age, $25-54$ years of age, $>55$ years of age). In addition, the data allow us to track matches between employers and employees. Thus, we are able to construct firm sizes by adding all individuals reported by the same employer at the end of each quarter and classified in small, medium and large $(<50$ employees, 50-250 employees, and >250 employees). Importantly, we can identify sectors at the 4-digit level according to ISIC codes adjusted for Colombia, which we can then classify into the 19 sectors used by Acemoglu and Restrepo (2020) to measure the degree of automation by sector. Finally, we have location of employment and we are, thus, able to identify each worker's corresponding local labor market.

Table 1 reports descriptive statistics for the Social Security database for 2016. About half of all formal workers are in firms with over 250 employees, $34 \%$ in firms with less 50 employees, and the rest are in medium-sized firms (50-250 workers). Over $74 \%$ of formal workers are between 25 and 54 years of age, $11 \%$ are less than 25 years old and $15 \%$ are older than 55 years of age. Less than half of formal workers in the PILA are women $(44 \%) .{ }^{12}$ Formal employment is concentrated in the capital (Bogota with 32.4\%) and accounts for more than $60 \%$ of national formal employment together with the next three largest commuting areas (Medellin, Cali and Barranquilla-Cartagena). Table 1 also shows that the proportion of those formally employed by the end of 2016 was $77 \%$. Table 1 also reports that out of those employed by the end of the third quarter, $14 \%$ of workers were separated from their jobs by the fourth quarter of 2016. The table also shows that, out of

\footnotetext{
${ }^{12}$ This percentage of women among formal workers is similar to those estimated using the National Household Survey, with $42 \%$ of female formal sector workers and $58 \%$ male.
} 
those not-formally-employed by the end of the third quarter of 2016, roughly half are hired into a formal sector job by the last quarter of 2016 .

\subsection{International Federation of Robotics (IFR) Data}

We use data from the International Federation of Robotics (IFR), which is a global Census of industrial robots. The IFR defines industrial robots as "automatically controlled, reprogrammable, and multipurpose [machines]" (IFR, 2015). The definition does not include industrial robots with single functionalities; other simple machines that by design require the interaction with humans -like self-checkouts or automated teller machines (ATMs); nor does it include software and artificial intelligence that also can replace human labor in the performance of tasks. The data is based on yearly surveys of robot suppliers from 1993 for 50 countries including the U.S., Colombia and European adopting countries. This corresponds to about 90 percent of the industrial robot market. It provides counts of the stock of robots by country, industry and year, with the implicit limitation that it treats equally a machine in the automotive sector as one in the textile sector without regard to their specific characteristics.

Robots are classified at a two-digit level into agriculture, forestry and fishing; construction; education, research and development; manufacturing; mining; other non-manufacturing, which includes services; and utilities. For the manufacturing industry there is a higher level of disaggregation at the three-digit level, which includes the following sectors: automotive; basic metals; electronics; foods and beverages; glass and ceramics; metal products; metal machinery; other vehicles; paper; plastics and chemicals; textiles; wood and furniture; and other manufacturing industries. ${ }^{13}$ Thus, we have information on robots in 19 sectors. We assigned the unclassified robots to the 19 industries

\footnotetext{
${ }^{13}$ This classification follows Acemoglu and Restrepo (2020).
} 
according with the distribution of the classified ones in the current year. ${ }^{14}$

We estimate the number of robots per thousand workers in the U.S. instead of total number of robots to understand the relation of robots to workers. We use 2008 employment data from the U.S. Census Bureau to estimate the denominator. The number of robots per thousand workers is highest in the automotive sector throughout the period, more than 9 times as much as the second largest sector in terms of adoption in 2011. The Electronics, Other Manufacturing ${ }^{15}$ and Basic Metals sectors have the largest increase in the number of robots per worker starting in 2010. In addition, other sectors (including Plastic and Chemical, Food and Beverages, Metal Machinery) have had a much steadier number of robots throughout the period. By contrast, the remaining sectors have a minimal number of robots throughout the period.

To complete our measure of exposure to robots we calculate the share of workers in each of the 19 sectors for which we have data in each local labor market using data from the Social Security records. For both workers with single a job and workers with multiple jobs, we weighted employment by the months of the year that they reported to be working. Table 2 reports the number and share of workers in each of the 19 sectors for all of Colombia. ${ }^{16}$ Other Non-manufacturing, which includes services, has close to $72 \%$ of all employment. Construction, Education and RD, Agriculture and Forestry and Mining and Quarrying are the four sectors with the next highest shares of employment $(5.7 \%, 4.4 \%, 4.3 \%$, and $4 \%$, respectively). Figure 1 shows the maps with the average exposure to U.S. robots measure across all industries, for all the 60 local labor markets in Colombia in 2011 and 2016. The maps depict LLM's with more exposure in a darker shade and those with less exposure

\footnotetext{
${ }^{14}$ There were $36 \%$ of the total stock of robots in the U.S. which were unclassified in 2011, but only $10 \%$ by 2016 .

${ }^{15}$ The other manufacturing sector considers economic activities such as: Jewelry and silverware manufacturing; sporting and athletic goods manufacturing; doll, toy, and game manufacturing; office supplies (except paper) manufacturing; sign manufacturing; gasket, packing, and sealing device manufacturing; musical instrument manufacturing; fastener, button, needle, and pin manufacturing; broom, brush, and mop manufacturing; burial casket manufacturing; and others.

${ }^{16}$ In our exposure measure, we calculate the share of each sector in each local labor market.
} 
in a lighter shade. The maps show that many LLM's have low exposure, which is not surprising given that exposure is greater in the manufacturing sectors and manufacturing production is highly concentrated in a few geographic locations in Colombia. ${ }^{17}$ Yet, we do see variation across the other areas and changes in exposure from 2011 to 2016. In addition, our estimates exploit not only the geographic variation shown in the maps, but also the industry variation described in the previous paragraph.

The number of robots in Colombia has grown over time but still remains very small. The growth in the number of robots used for production in Colombia increased from a total of 19 robots in 2011 to 124 robots in the whole country by 2016 , (with close to $80 \%$ of these robots concentrated in plastics and chemicals, basic metals, and automotive sectors). Thus, the number of domestic robots is still too small to try to infer its distribution across local labor markets in a way analogous to the way we built the exposure to U.S. robots measure. Instead, we assume that their effects are still negligible at the local labor market level.

We also use the IFR data to build the measure of exposure to European robots that we use as an instrument in the two-stage least squares procedure. Following Acemoglu and Restrepo (2020), we use the adoption in the 19 industries in the Netherlands, France, Spain, Sweden and UK. We use employment data from the International Labor Office to get the stock of robots per worker in each country.

\subsection{Export and Import Data}

To provide evidence on the potential mechanism behind the effects of robots adopted in the U.S. on the employment and earnings of Colombian workers, we exploit granular data on bilateral trade.

\footnotetext{
${ }^{17}$ This was documented in detail by Ellison, Glaeser and Kerr (2010).
} 
Our data reports exports and imports, to and from a particular destination for each 4-digit product of the Harmonized System (HS), for each municipality in Colombia and for each year from 2008 to 2014. We aggregate the exports and imports separately at the local labor market level and we use the variable lagged three years to avoid endogeneity concerns. ${ }^{18}$ Finally, we divide exports/imports by the Value Added disaggregated at the same LLM level ${ }^{19}$ for the earliest year available, in order to weight by the economic activity of the market as we do not want the volume of exports just to capture the fact that an LLM is larger but instead we want to capture the importance of exports/imports in each particular LLM.

Panel A of Figure 2 presents a map with the geographic variation of the exports per value added of Colombia's local labor markets in 2011. Panel B of Figure 2 shows the intensity of imports per value added across local labor markets. By inspection, one can see that there is a high correlation of these two variables. This geographic pattern reflects the fact that exports and imports are concentrated in a few markets (as documented by Eaton et al., 2008), but we still substantial variation across local labor markets.

According to export information processed by the National Administrative Department of Statistics (DANE) and the National Taxes and Customs Department (DIAN), in 2016 the country's external sales were U\$32.9 billion. In 2016, the United States was the main destination for Colombian exports, with a $32 \%$ share in the total value exported, followed by Panama with only 5.8 percent. According to import declarations filed with DIAN in 2016 , imports were US $\$ 43.2$ billion. The U.S. is the largest importer to Colombiawith $26.8 \%$ of total Colombian imports coming from the U.S., followed by China with 19.6\%, Mexico with $7.8 \%$ and Brazil with $4.9 \%$. As mentioned

\footnotetext{
${ }^{18}$ We chose a three-year lag to capture permanent relations in export/import relations within sectors between the U.S. and Colombia. We tried different lags and the results are robust to various specifications.

${ }^{19}$ We have data on Value Added at the municipality level from DANE Cuentas Nacionales for 2008.
} 
above, we control for trade with China in our specifications below to check the robustness of our results to the fact that China is Colombia's second largest trading partner.

\subsection{Informality Data}

A potential limitation of the Social Security data is that it only covers formal employment. While we cannot distinguish informal and unemployed workers in our data, we can examine if our impacts are greater or smaller in LLMs where the informal sector is larger. To do this, we use the labor informality rate across regions, which is measured as the proportion of working population participating in economic activities out of the formal sector. This is measured by DANE for the main 23 cities and metropolitan areas in Colombia, which coincide with 23 of our LLM's. These data show that the proportion of working population in the informal sector ranged from 48 and 52 percent in the period between 2011 and 2016.

\section{Impact of U.S. Robots on Colombian Labor Markets}

\subsection{Overall Effects of U.S. Robots on Employment, Wages and Turnover}

In this section, we present our results on the impacts of U.S. robots on Colombian labor markets.

We examine not only the impacts of the adoption of U.S. robots on employment and earnings of Colombian workers, but also the impacts on hires and dismissals on those sectors and local labor markets most affected by robot adoption in the U.S.

Panel A in Table 3 presents results of the impacts of industry exposure to U.S. robots on labor markets in Colombia estimating equation (2) for our four outcome variables of interest, using the full sample, and controlling for seasonal, year, industry and local labor market fixed effects. It is worth noting that for the likelihood of being employed, getting fired of hired we estimate a Linear 
Probability Model, while for wages we estimate a standard Mincer equation. Columns (1) and (2) show effects of industry exposure to U.S. robots on employment and log wages in those local labor markets where those industries have been a high share of employment in the past. These results show decreases in employment and earnings for Colombian workers. These effects on both employment and earnings suggest a labor demand shift to the left in those sectors of the local economy where robots are coming in the U.S. Columns (3) and (4) also show impacts on labor turnover as a result of exposure to U.S. robots. There is an increase in dismissals for workers in sectors highly impacted by robots in the U.S. In addition, there is a decrease in hiring in sectors in LLM's with high levels of robotization, though this effect is not significant. Thus, increased dismissals account for lower employment in Colombian labor markets most affected by U.S. robots.

To understand the estimated magnitudes, consider the local labor market of Apartado, near Medellin (the country's second largest city) in the state of Antioquia, which ranks among the bottom three regions in terms the exposure to U.S. robots, with an average level of 0.5 from 2011 to 2016. If Apartado would have increased its level of exposure to robots as much as Magangue, the second largest city in the state of Bolivar only after Cartagena (Colombia's fifth largest city) which has an average level of exposure to robots of 1.4 over the same period, positioning it as the top two local labor market in our measure of exposure to robots. This hypothetical increase in the average level of exposure to U.S. robots for Apartado's to Magangue's average level of exposure to robots from 2011 to 2016, the likelihood of employment of a worker in Apartado would decrease by $0.2 \%^{20}$ and the likelihood of dismissal would increase by $0.8 \%$. Likewise, wages would fall by $1.6 \% .^{21}$

\footnotetext{
${ }^{20}$ The calculation of $0.2 \%$ decrease in the likelihood of employment from our estimated coefficient, goes as follow: (ExposuretoRobots $s_{i, c=\text { Magangue }}-$ ExposuretoRobots $\left._{i, c=\text { Apartado }}\right) \times \hat{\rho}=(1.40-0.5) \times(-0.0014)=-0.0013$, which is the around $0.2 \%$ of 0.77 , the average likelihood of being employed in the whole sample (see Table 1 ).

Similarly, for wages $(1.40-0.5) \times(-0.0178)=-0.016$, which means an effect of $1.6 \%$ since is a semi elasticity.

${ }^{21}$ The estimated coefficients with the LPM are robust to model specification, we checked that by running the
} 
A reasonable concern to our estimates might be that areas with different levels of exposure to foreign robotization are systematically different in terms of other characteristics (which we control for), but also that those areas could be following different trends across time. To control for this possibility, we add to our baseline regression a dummy for each of the 32 states or Departments, interacted with a time trend. Panel B of Table 3 shows that our results including Departmentspecific trends are not significantly different to those in Panel A, confirming that our estimated impacts are robust and not merely capturing differences in labor market trends across regions.

As discussed in Section 4.2., the automotive sector had the highest stock of robots in the U.S. more than $40 \%$ of the total amount of robots throughout the entire period of study, so we examine if the results are driven simply by this sector. Panel $\mathrm{C}$ of Table 3 shows results leaving out the automotive sector, since this sector is an outlier in terms of U.S. robot adoption. We find that the results are robust to the exclusion of the automotive sector, as the magnitude of the effects on employment, wages and dismissals are slightly smaller and not significantly different from those including the automotive sector and the effect on hiring continues to be insignificant.

Finally, in Panel D of Table 3, we control for import competition from China for LLMs, by adding to equation (2) the three years lagged value of Colombian imports from China relative to GDP at the LLM level. After 2001, the trade between Colombia and China increased drastically, so we may be concerned that those same sectors affected by U.S. robots are also affected by trade with China. Indeed, Cardenas and Kugler (2011) and Molina (2020) provide evidence of a "China effect" in Colombia impacting the orientation and speed of structural transformation in manufacturing. However, we verify that the effects with the control for Chinese imports are virtually the same as those without this control.

baseline regression with a logit model instead of LPM. The marginal effects calculated with all the variables in their mean values are presented in Table A1 of the Appendix. 


\subsection{Heterogenous Effects of U.S. Robots on Colombian Workers}

In Table 4, we present the differential impact of exposure to U.S. robots on different types of workers. Panel A presents results of models with interactions with a female dummy to examine if the effects are larger for women than men. Column (1) of Panel A shows negative effects on the probability of employment of similar magnitude for men and women. Similarly, Column (3) shows positive impacts of U.S. robots on the probability of a separation, which are not significantly different for men and women. By contrast, the results in Columns (2) and (4) show that the negative effect U.S. robots on wages and hiring have been larger for women than for men. Moreover, we find that the negative effect of U.S. robots on hiring falls completely on women and does not affect men. This suggests that women's wages and hiring may be adjusting before the adjustment of employment and dismissals, which are subject to high costs in Colombia.

Panel B in Table 4 presents models with interactions for different age groups to examine whether younger or older workers have been most affected by U.S. robots. We include interactions of exposure to U.S. robots with a 25 to 34 -year-old dummy, a 35 to 54 -year-old dummy and a dummy for those older than 55 years of age, where the excluded category is the group younger than 25 years of age. Columns (1) and (2) show that the negative impacts on employment and earnings are driven by older workers. The employment results also show significant negative impact on the employment of middle-aged workers. Column (3) shows positive impacts of US robots on dismissals were experienced by all age groups except the under 25-year-old group. U.S. robots are, indeed, more likely to replace the work of older workers than younger workers. However, the effect is greatest for the over 55 group, then for the middle-aged group and smallest for the 25 to 34 -yearold group. By contrast, the effect of US robots on reduced hires affected only the oldest group. The fact that the oldest group of workers experienced the largest negative effects on employment, wages 
and turnover, while the youngest group had no significant effects associated with the intensification of U.S. robot adoption, is consistent with the higher flexibility of new generations to adjust to changes in the labor market demand.

Table 5 instead examines the impact of U.S. robots on different types of firms. We report results from interaction models with a small-sized firm dummy (less than 50 employees) and a mediumsized firm (between 50-250 employee) dummy, where the excluded group includes firms with more than 250 employees. We find that the effect of U.S. robots is greater on small and medium sized firms compared to larger firms with more than 250 employees, which may be in a better position to compete technologically with U.S. firms. Columns (1) and (4) show negative effects of U.S. robots on the likelihood of employment and hiring for both small and medium-sized firms. Large firms do not decrease their likelihood of employment, but they do reduce the probability of hiring. By contrast, Column (2) shows negative effects of robots only on the earnings of those employed in medium-sized firms. Like for employment and hiring, the positive impacts of robots on dismissals in Column (3) are larger for workers employed in small and medium-sized firms than for larger firms, though the effect on small firms is only marginally significant. These results, thus, show that the effects of U.S. robots are greatest for those employed in firms that are in a weaker position to compete with robotization.

Table 6 shows effects on different sectors by interacting sector dummies with the U.S. exposure to robots. The results show bigger negative impacts of robots on employment, hiring and wages and greater positive effects on dismissals in the automotive, electronics, food and beverage, metal, and other manufacturing sectors. These negative effects may suggest that sectors that used to export Colombian products to the U.S. are now being replaced by robot-intensive manufacturing of these products in the U.S. By contrast, there are no differential effects in the paper, textile and 
wood and furniture sectors and positive effects in the construction and education sectors.

Overall, the effects are greater on the groups most likely to be affected by competition from robots, including women, older workers, and workers in smaller firms. We also find bigger effects in certain sectors. In Section 5.4., we explore if the difference in impacts across sectors is driven by the extent of heterogeneity in export and import shares to and from the U.S.

\subsection{Other Robustness Checks: IV Estimates and the Role of Informality}

In the previous section, we provided evidence of the effects of robotization abroad on Colombian labor markets and we showed that our results were robust to industry-specific shocks, regional trends, and China's import competition. In this section we address possible endogeneity concerns of robots as well as the role of informality on mitigating or amplifying the effects of exposure to U.S. robots.

\subsubsection{Estimates}

A potential issue with the OLS regressions presented in the previous section is that the effect of robotization in the U.S. biased due to measurement error coming from the way unclassified robots were assigned to specific sectors; due to correlation with unobservables such as the existence of a global shock -like the 2008 financial crisis- differentially affecting industries' employment in Colombia in the same way as robot adoption in the U.S.; or due to endogeneity if robotization in certain sectors in the U.S. is driven by competition from lower-income countries and that may affect labor market outcomes in these countries. While in Footnote 6 we note that we deem the likelihood of endogenity remote, we still consider this robustness check worthwhile also in order to correct from the potential bias from measurement error in unclassified robots. 
To address this issue, we instrument robotization in the U.S. with robotization in Europe. Since the trade between Europe and Colombia is not as extensive as U.S.-Colombia trade, it is reasonable to assume that the exclusion restriction holds and robotization in Europe is not related to other sectoral shocks in Colombia. The combined imports coming from all five European countries adopting robots -Netherlands, France, Spain, Sweden and the U.K.- ${ }^{22}$ used as an instrument represent around $6 \%$ of the value of total imports, while the exports going to those countries combined represent less than 10\%. Figure 3 show that robotization in Europe is indeed strongly related to robotization in the U.S. Panel B of Table 7 shows the first-stage. Since we use the same instrument in all four specifications, the results are almost the same, with small variations due to the sample differences (specifically for the hirings and separations) and show a positive relation between robot adoption in Europe and robot adoption in the U.S. An increase of one additional robot per thousand employees in Europe increases robots in the U.S. by 3.6 robots per thousand employees. The F-test also confirms the relevance of our instrument.

Panel A of Table 7 shows the two-stage least square (2SLS) estimates for the four outcome variables of interest. In all cases, the 2SLS estimates have the same sign although the magnitudes are smaller and, as expected, somewhat less precise. The results suggest a $30 \%$ upward bias in the OLS estimates.

\subsubsection{The Role of Informality}

Finally, we analyze whether the effects of the exposure to U.S. robots, documented in previous sections, become larger or smaller when informality is more or less prevalent in Colombian LLM's. This empirical question has been unexplored by the literature because most of previous work on

\footnotetext{
${ }^{22}$ We consider these five countries for having good quality data and having a representative adoption of the region. We exclude countries with very low adoption or very high adoption such as Germany.
} 
the topic has focused on developed countries. Nevertheless, in the case of developing countries like Colombia, where labor informality represents roughly $50 \%$ of the work force, this phenomenon cannot be overlooked. We add to equation (2) the official measure of the size of labor informality as a control, as well as the interaction of this variable with the exposure to U.S. robots.

Table 8 present the results with the interaction between the robots and the share of informality as well as the main effect of informality for each of our four outcome variables of interest. Columns (1), (2) and (4) show that exposure to robots has a less negative effect on employment, wages and hires and the positive effect of robots on separations is smaller when informality is greater. There are two potential reasons for this. First, the informal sector may act as a scape valve against exposure to robots from abroad by allowing workers to hold a second job in the informal sector. A second way in which a larger informal sector can reduce the negative impact of robots is if the informal sector supplies the formal sector with cheaper supplies that allow the formal sector to stay competitive internationally.

\subsection{Is Reshoring Causing Colombian Workers to Lose their Jobs to U.S. Robots?}

In the previous section, we found that U.S. robots largely worsen labor market conditions for Colombian formal workers in the short run through displacement. In this section, we examine if this is due to a reduction of Colombian exports to the U.S. from sectors that are becoming increasingly more automated through robot adoption in the U.S. It is likely that as it becomes more efficient to produce in the U.S. with robots, the comparative advantage of these automated sectors flips back to the U.S. relative to these sectors in Colombia, as capital-intensive production becomes less costly than labor-intensive production so that manufacturing components in labor-abundant Colombia is no longer the optimal location. U.S. robots make possible more efficient manufacturing 
by also lowering transportation costs due to proximity to final-good assembly facilities. Reshoring of production back to the U.S. becomes more attractive than exporting from Colombia to the U.S. Coming back to the example in the introduction, the Group Phoenix, the U.S. packaging manufacturing company based in Colombia, reshored production bringing new jobs back to the U.S. and reducing employment in Colombia.

It is important to highlight that part of the potential job loss due to reshoring can be related to direct effects of local suppliers but also to indirect effects. The displacement can affect not only workers directly employed in the supplier firm exporting components to the U.S. but also displacement of workers in firms supplying intermediate inputs and services downstream through backward linkages with the Colombian firms selling components through GVCs. ${ }^{23}$ These generalequilibrium effects can be captured within our 19 sectors -given how broad in scope they are.

Table 9 shows results of estimating equation (4), i.e. the model that interacts the exposure to U.S. robots with a 3-year lag of U.S. exports from and U.S. imports to a given local labor market. We also control for the 3-year lag of U.S. imports and U.S. exports to each local labor market in each sector in these regressions. Columns (1)-(4) show coefficients of the direct and interaction terms for employment, wages, dismissals and hires.

As expected, imports themselves reduce employment and earnings in those sectors. More importantly, we find negative coefficients in the interaction terms between exports and exposure to U.S. robots in the employment and wage regressions. That means that the impacts of U.S. robots on employment and wages were more adverse in local labor markets where sectors had greater prior exports. In addition, we find that the positive impact of U.S. robots is also bigger on dismissals in those sectors previously exporting their products to the U.S. These results point to the GVC

\footnotetext{
${ }^{23}$ Kugler (2006) shows the importance of these backward linkages for the case of FDI in Colombia.
} 
channel, whereby U.S. firms relocate component production away from Colombia, as a potential explanation of U.S. robots depressing labor demand in Colombian exporting industries.

To illustrate the magnitudes of the results, consider again the local labor market of Mangague, which given its labor market structure has a level of exposure to U.S. robots of 1.4. Suppose that three years ago, instead of its level of exports to GDP ratio (0.0002), Magangue had Apartado's level of exports also weighted by its economic activity (0.1373). Our estimated coefficients suggest that this higher intensity of exports in the past would decrease the likelihood of employment by $0.2 \%^{24}$ and increase the likelihood of separation by $0.02 \%^{25}$, while it would reduce workers' wages by $1.8 \% .^{26}$

These results show that workers employed in industries in LLM's, which exported the most to the U.S. in the past, are the most affected by the increased adoption of U.S. robots. These findings, thus, suggest that efficiency gains driving rising robot use may indeed be causing U.S. firms to start producing either final goods or intermediate inputs again domestically. This reshoring may be contributing to job losses in Colombia, and to the lower employment and wages as automation rises in the U.S.

\section{Conclusions}

The impacts of automation reach well beyond the shores and boundaries of a single country. In this paper, we find that the adoption of robots in the U.S. has important impacts on Colombian workers. Our findings suggest that this is because the U.S. can respond by reshoring production in reaction to greater robot adoption in the U.S. manufacturing sector, instead of importing from Colombia.

\footnotetext{
${ }^{24}$ The calculation of the decrease of $0.2 \%$ of the likelihood of being employed is as follows: $(0.1373-0.0002) \times$ $(-0.0099)=0.1371 \times(-0.0099)=-0.0014,0.2 \%$ of 0.77 , the average likelihood of being employed.

${ }^{25} 0.1371 \times(-0.0084)=-0.0012,0.02 \%$ of 0.14 , the average likelihood of a separation.

${ }^{26} 0.1371 \times(-0.129)=0.018$, i.e. an effect of $1.8 \%$ since is a semi-elasticity.
} 
Thus, even though Colombia has been a laggard in terms of domestic robot adoption, automation in the U.S. can impact labor market outcomes in Colombia by reducing export prospects as cheaper robot production makes relocation back to the U.S. more attractive.

We use unique employer-employee micro-data from Colombia combined with data on robot adoption for the U.S. from the International Federation of Robots to examine whether U.S. robots displace Colombian workers. We find that greater adoption of U.S. robots in a sector that accounts for a high employment share in a local labor market in Colombia reduces formal employment and wages. In addition, we find that the fall in employment due to robotization in the U.S. comes both from an increase in dismissals of Colombian workers as well as a reduction in hires.

The negative effects of U.S. robots are greatest for those workers who are already more vulnerable in terms of their labor market experience and incomes in the formal sector in Colombia. We find that U.S. robots have bigger negative impacts in terms of employment, wages, and turnover on women and older workers. Moreover, the effects are larger for workers employed by SMEs. This means that automation in Colombia likely has adverse distributional impacts and exacerbates the already substantially skewed income inequality in the country.

Importantly, we find that the effects of U.S. robots on worker displacement in Colombia is greater in local labor markets dominated by sectors that exported more to the U.S. in the past. U.S. robots, thus, appear to replace Colombian workers who were previously producing intermediate inputs or final goods to export to the U.S. Thus, robotization in the U.S. seems to enable reshoring of production to the U.S. of goods previously manufactured and imported from countries that used to hold a comparative advantage because of lower wages.

In comparison to prior estimates of the employment effect of an additional U.S. robot, our OLS estimates suggest that one more robot in the U.S. reduces formal Colombian employment by about 
1.2 to 1.4 workers, and slightly less than a full worker per our IV estimate. ${ }^{27}$ From 2011 to 2016, our period of analysis, the U.S. adopted about 70,000 new robots, which would lead to a cumulative loss in the range of 63,000 and 100,000 jobs in Colombia. ${ }^{28}$ This might not seem particularly large over half a decade. ${ }^{29}$ However, it is significant if we consider that this is the effect of U.S. robots after substituting away directly U.S. labor as estimated by Acemoglu and Restrepo (2020), and also indirectly displacing workers also of other U.S. trading partners, such as Mexico. ${ }^{30}$ Indeed, the analogous estimate by Acemoglu and Restrepo (2020) is that each extra robot generates job losses for 6 workers in the U.S. - and over 2000-2016 each additional robot per thousand workers lowered employment-to-population ratio growth by 0.37 percentage points.

Our paper contributes to the existing literature on automation by examining the impact of robotization by a developed country on labor market outcomes in a developing country. The most likely channel underlying our evidence is the trade channel, with producers interconnected through GVCs impact each other's optimal location choices and technology can reconfigure the best place to produce. We also add to the literature by providing more disaggregated measures of labor market outcome effects, including on employment, wages and turnover, and by examining the distributional impacts of robots in a developing country.

\footnotetext{
${ }^{27}$ For an order of magnitude to serve as benchmark, the employment effect estimated by Molina (2020) of the China Syndrome in Colombia for the $2000-2010$ period was a decline of $2.5 \%$ on employment growth.

${ }^{28}$ Given that the number of unemployed in Colombia was 2.3 million in 2016, if the displacement from robots was distributed equally across years, then this would account for only about $1 \%$ of all the unemployed in Colombia at the time.

${ }^{29}$ BCG (2015) projected two scenarios for robot adoption growth from 2016 to 2025 . In their conservative scenario, the stock of robots was forecasted to experience a threefold increase, and in the other one robot deployment would quadruple. With the COVID-19 slowdown, the former scenario appears more likely. Although, fear of future similar pandemics may actually accelerate robot use in some sectors and occupations. Ceteris paribus, our estimates will translate into half million to 700,000 jobs lost over a decade associated with U.S. robot adoption under a business as usual scenario. Or, possibly, if robot use accelerates, the number of formal jobs lost in Colombia could reach over a million.

${ }^{30}$ See Faber (2020).
} 


\section{References}

Acemoglu, D., C. LeLarge, P. Restrepo. 2020. "Competing with Robots: Firm-Level Evidence from France," AEA Papers and Proceedings, 110:383-88.

Acemoglu, D. and P. Restrepo. 2020. "Robots and Jobs: Evidence from US Labor Markets," Journal of Political Economy, 128(6): 2188-2244.

Amiti, M. and A. Khandelwal. 2013. "Import Competition and Quality Upgrading," Review of Economics and Statistics, 92(2): 476-490.

Artuc, E., L. Christiaensen and H. Winkler. 2019. "Does Automation in High-Income Countries Hurt Developing ones? Evidence from the United States and Mexico," Policy Research Working Paper No. 8741, The World Bank, Washington, DC.

Artuc, E., P. Bastos and B. Rijkers, Bob. 2018. "Robots, Tasks and Trade," Policy Research Working Paper No. 8674, The World Bank, Washington, DC.

Autor, D. and A. Salomons. 2018. "Is Automation Labor Share-Displacing? Productivity Growth, Employment, and the Labor Share," Brookings Papers on Economic Activity, (Spring):163.

Boston Consulting Group. 2015. "The Robotics Revolution: The Next Great Leap in Manufacturing." BCG perspectives.

Cardenas, M. and A. Kugler. 2011. "The Reversal of the Structural Transformation in Latin America After China's Emergence," Brookings Working Paper, Washington, D.C.

Dinlersoz, E. and Z. Wolf. 2018. "Automation, Labor Share, and Productivity: Plant-Level Evidence from U.S. Manufacturing," U.S. Census Bureau Working Papers 18-39, CES.

Eaton, J., M. Eslava, M. Kugler and J. Tybout. 2008. "The Margins of Entry into Export Markets: Evidence from Colombia" in Helpman, E., D. Marin and T. Verdier (eds.) The Organization of Firms in a Global Economy, 1453-98, Cambridge, MA., Harvard U. Press.

Eslava, M., Haltiwanger, J., Kugler, A. and Kugler, M., 2013. "Trade and Market Selection: Evidence from Manufacturing Plants in Colombia," Review of Economic Dynamics, 16(1):135-158. 
Faber, M. 2020. "Robots and Reshoring: Evidence from Mexican Labor Markets", forthcoming Journal of International Economics, Volume 127, November.

Graetz, G. and G. Michaels. 2018. "Robots at Work", Review of Economics and Statistics, 100(5):753-768.

Hallward-Driemeier, M. and G. Nayyar. 2019. "Have Robots Grounded the Flying Geese?: Evidence from Greenfield FDI in Manufacturing," Policy Research Working Paper No. 9097, The World Bank, Washington, D.C..

Khandelwal, A. 2010. "The Long and Short (of) Quality Ladders," Review of Economic Studies, $77(4): 1450-1476$.

IFR. 2015. "World Robotics 2015," Technical Report, International Federation of Robotics.

Kinkel, S., A. Jager, C. Zanker. 2015. "The effects of robot use in European manufacturing companies on production offshoring outside the EU," International Annual EurOMA Conference, Neuchâtel, Switzerland.

Krenz, A., Prettner, K. and Strulik, H. 2018. "Robots, Reshoring, and the Lot of Low-Skilled Workers," Working Paper No. 351, CEGE.

Kugler, M. 2006. "Spillovers from foreign direct investment: Within or between industries?" Journal of Development Economics, 80 (2), pp. 444-477.

Kugler, M. and E. Verhoogen. 2009. "Plants and Imported Inputs: New Facts and Interpretation," American Economic Review, 99(2): 501-507.

Kugler, M. and E. Verhoogen. 2012. "Price, Plant Size, and Product Quality," Review of Economic Studies, 79(1): 307-339.

Molina, D. 2020. "The China Effect on Colombia's Manufacturing Labor Market," Working Paper Series No. 01101, IDB, Washington D.C.

Sanchez-Serra, D. 2016. "Functional Urban Areas in Colombia", Regional Development Working Papers 2016/08, OECD Publishing, Paris.

Topalova, P. and Khandelwal, A. 2011. "Trade Liberalization and Firm Productivity: The Case of India," Review of Economics and Statistics, 93(3): 995-1009. 
Table 1: Descriptive Statistics, 2016

\begin{tabular}{|c|c|}
\hline Variable & 2016 \\
\hline Exposure to U.S. Robots & $\begin{array}{c}1.49 \\
(6.08)\end{array}$ \\
\hline Formal Employment status & $\begin{array}{c}0.77 \\
(0.42)\end{array}$ \\
\hline Separations & $\begin{array}{c}0.14 \\
(0.35)\end{array}$ \\
\hline Hirings & $\begin{array}{l}0.49 \\
(0.5)\end{array}$ \\
\hline Wages $^{1}$ & $\begin{array}{l}\$ 1,114,250 \\
(7,545,966)\end{array}$ \\
\hline Gender (female) & $\begin{array}{c}0.43 \\
(0.49)\end{array}$ \\
\hline Age group & \\
\hline Less than 25-year-old & $\begin{array}{c}0.21 \\
(0.41)\end{array}$ \\
\hline 25 to 34 -year-old & $\begin{array}{c}0.31 \\
(0.46)\end{array}$ \\
\hline 35 to 54-year-old & $\begin{array}{c}0.39 \\
(0.49)\end{array}$ \\
\hline 55-year-old or more & $\begin{array}{c}0.9 \\
(0.29)\end{array}$ \\
\hline Firm size & \\
\hline Small $(<50)$ & $\begin{array}{c}0.35 \\
(0.48)\end{array}$ \\
\hline Medium (50-250) & $\begin{array}{c}0.19 \\
(0.39)\end{array}$ \\
\hline Large $(>250)$ & $\begin{array}{l}0.45 \\
(0.5)\end{array}$ \\
\hline Total number of observations & $32,820,586$ \\
\hline
\end{tabular}


Table 2: Employment Distribution Across Sectors

\begin{tabular}{lcc}
\hline \hline & Number of workers & Share \\
\hline Agriculture and forestry & $1,410,929$ & $4.30 \%$ \\
Automotive & 59,085 & $0.18 \%$ \\
Basic Metals & 82,575 & $0.25 \%$ \\
Construction & $1,875,917$ & $5.72 \%$ \\
Education and R\&D & $1,443,506$ & $4.40 \%$ \\
Electricity, gas and water supply & 274,518 & $0.84 \%$ \\
Electronics & 93,479 & $0.28 \%$ \\
Food and beverages & 753,645 & $2.30 \%$ \\
Glass and ceramics & 99,676 & $0.30 \%$ \\
Metal Machinery & 94,233 & $0.29 \%$ \\
Metal Products & 159,606 & $0.49 \%$ \\
Mining and Quarrying & $1,322,233$ & $4.03 \%$ \\
Other Vehicles & 5,466 & $0.02 \%$ \\
Other manufacturing & 241,935 & $0.74 \%$ \\
Other non manufacturing & $23,503,510$ & $71.61 \%$ \\
Paper & 162,464 & $0.50 \%$ \\
Plastic and chemical & 407,414 & $1.24 \%$ \\
Textiles & 676,894 & $2.06 \%$ \\
Wood and furniture & 153,501 & $0.47 \%$ \\
\hline Total & $32,820,586$ & $100 \%$ \\
\hline \hline
\end{tabular}

Source: PILA (Colombian Social Security Records), 2016. 
Table 3: Effects of US Robots on Employment, Wages, Separations and Hires

\begin{tabular}{|c|c|c|c|c|}
\hline & $\begin{array}{c}(1) \\
\text { Employment }\end{array}$ & $\begin{array}{c}(2) \\
\text { Log Wages }\end{array}$ & $\begin{array}{c}(3) \\
\text { Separation }\end{array}$ & $\begin{array}{c}(4) \\
\text { Hiring }\end{array}$ \\
\hline \multirow[b]{2}{*}{ Exposure to US robots } & \multicolumn{4}{|c|}{ Panel A. Baseline } \\
\hline & $\begin{array}{c}-0.0014^{* * *} \\
(0.0004)\end{array}$ & $\begin{array}{c}-0.0178^{* * * *} \\
(0.0063)\end{array}$ & $\begin{array}{c}0.0012^{* * *} \\
(0.0002)\end{array}$ & $\begin{array}{l}-0.0007 \\
(0.0007)\end{array}$ \\
\hline No. Observations & $226,450,548$ & $226,450,540$ & $172,462,095$ & $53,988,453$ \\
\hline \multirow[b]{2}{*}{ Exposure to US Robots } & \multicolumn{4}{|c|}{ Panel B. Including Regional Trends } \\
\hline & $\begin{array}{c}-0.0014^{* * *} \\
(0.0003)\end{array}$ & $\begin{array}{c}-0.0182^{* * *} \\
(0.0058)\end{array}$ & $\begin{array}{c}0.0012^{* * *} \\
(0.0002)\end{array}$ & $\begin{array}{c}-0.0008 \\
(0.0006)\end{array}$ \\
\hline No. Observations & $226,450,548$ & $226,450,540$ & $172,462,095$ & $53,988,453$ \\
\hline \multirow[b]{2}{*}{ Exposure to US robots } & \multicolumn{4}{|c|}{ Panel B. Excluding Automotive Industry } \\
\hline & $\begin{array}{c}-0.0013^{* * *} \\
(0.0003)\end{array}$ & $\begin{array}{c}-0.0171^{* * *} \\
(0.0059)\end{array}$ & $\begin{array}{c}0.0011^{* * *} \\
(0.0002)\end{array}$ & $\begin{array}{l}-0.0008 \\
(0.0007)\end{array}$ \\
\hline No. Observations & $226,057,997$ & $226,057,989$ & $172,130,224$ & $53,927,773$ \\
\hline \multirow[b]{2}{*}{ Exposure to US robots } & \multicolumn{4}{|c|}{ Panel D. Controlling for Chinese Imports } \\
\hline & $\begin{array}{c}-0.0014^{* * *} \\
(0.0004)\end{array}$ & $\begin{array}{c}-0.0179^{* * *} \\
(0.0062)\end{array}$ & $\begin{array}{c}0.0012^{* * *} \\
(0.0002)\end{array}$ & $\begin{array}{c}-0.0008 \\
(0.0007)\end{array}$ \\
\hline No. Observations & $226,450,548$ & $226,450,540$ & $172,462,095$ & $53,988,453$ \\
\hline
\end{tabular}

Note: The table reports coefficients of linear probability models for employment, hiring and separation probabilities and regression coefficient of a linear model for log wages. All regressions control for a female dummy, three age group dummies (25-34, $35-54$, and $>55$ years old) and two firm size dummies for small ( $<50$ employees) and medium-sized firms (50-250 employees). We also include quarter, year, industry and local labor market fixed effects. Standard errors are clustered at the state level and included in parenthesis. ${ }^{*},{ }^{* *}$ and ${ }^{* * *}$ denote statistical significance at the $10 \%, 5 \%$ and $1 \%$ level respectively. 
Table 4: Effects of Robots by Gender and Age

\begin{tabular}{|c|c|c|c|c|}
\hline & $\begin{array}{c}(1) \\
\text { Employment }\end{array}$ & $\begin{array}{c}(2) \\
\text { Log Wages }\end{array}$ & $\begin{array}{c}(3) \\
\text { Separation }\end{array}$ & $\begin{array}{c}(4) \\
\text { Hiring }\end{array}$ \\
\hline \multirow[b]{2}{*}{ Exposure to US robots } & \multicolumn{4}{|c|}{ Panel A. Effects by Gender } \\
\hline & $\begin{array}{c}-0.0012^{* *} \\
(0.0005)\end{array}$ & $\begin{array}{r}-0.0136^{*} \\
(0.0077)\end{array}$ & $\begin{array}{c}0.0011^{* * *} \\
(0.0003)\end{array}$ & $\begin{array}{l}-0.0004 \\
(0.0007)\end{array}$ \\
\hline $\begin{array}{l}\text { Exposure to US Robots } \times \\
\text { Female Dummy }\end{array}$ & $\begin{array}{l}-0.0005 \\
(0.0003)\end{array}$ & $\begin{array}{c}0.0130^{* * *} \\
(0.0042)\end{array}$ & $\begin{array}{c}0.0003 \\
(0.0003)\end{array}$ & $\begin{array}{c}-0.0012^{* * *} \\
(0.0003)\end{array}$ \\
\hline \multirow[b]{2}{*}{ Exposure to US robots } & \multicolumn{4}{|c|}{ Panel B. Effects by Age Group } \\
\hline & $\begin{array}{l}-0.0006 \\
(0.0004)\end{array}$ & $\begin{array}{l}-0.0070 \\
(0.0077)\end{array}$ & $\begin{array}{c}0.0001 \\
(0.0003)\end{array}$ & $\begin{array}{l}-0.0004 \\
(0.0008)\end{array}$ \\
\hline $\begin{array}{l}\text { Exposure to US robots } \times 25 \text { to } \\
34 \text {-year-old }\end{array}$ & $\begin{array}{l}-0.0004 \\
(0.0003)\end{array}$ & $\begin{array}{l}-0.0070 \\
(0.0053)\end{array}$ & $\begin{array}{c}0.0009^{* * *} \\
(0.0002)\end{array}$ & $\begin{array}{l}-0.0003 \\
(0.0003)\end{array}$ \\
\hline $\begin{array}{l}\text { Exposure to US robots } \times 35 \text { to } \\
54 \text {-year-old }\end{array}$ & $\begin{array}{c}-0.0010^{* * *} \\
(0.0004)\end{array}$ & $\begin{array}{c}-0.0146^{* *} \\
(0.0067)\end{array}$ & $\begin{array}{c}0.0016^{* * *} \\
(0.0002)\end{array}$ & $\begin{array}{l}-0.0003 \\
(0.0003)\end{array}$ \\
\hline $\begin{array}{l}\text { Exposure to US robots } \times 55 \text { - } \\
\text { year-old or more }\end{array}$ & $\begin{array}{c}-0.0031^{* * *} \\
(0.0005)\end{array}$ & $\begin{array}{c}-0.0371^{* * *} \\
(0.0084)\end{array}$ & $\begin{array}{c}0.0028^{* * *} \\
(0.0003)\end{array}$ & $\begin{array}{c}-0.0014^{* *} \\
(0.0005)\end{array}$ \\
\hline No. Observations & $226,450,548$ & $226,450,540$ & $172,462,095$ & $53,988,453$ \\
\hline
\end{tabular}

Note: The table reports coefficients of linear probability models for employment, hiring and separation probabilities and regression coefficient of a linear model for log wages. All regressions control for a female dummy, three age group dummies $(25-34,35-54$, and $>55$ years old) and two firm size dummies for small ( $<50$ employees) and medium-sized firms (50-250 employees). We include quarter, year, industry and local labor market fixed effects. Standard errors are clustered at the state level and included in parenthesis. ${ }^{*}, * *$ and ${ }^{* * *}$ denote statistical significance at the $10 \%, 5 \%$ and $1 \%$ level respectively. 
Table 5: Effects of Robots by Firm Size

\begin{tabular}{lcccc}
\hline \hline & Employment & Log Wages & Separation & Hiring \\
\hline Exposure to US robots & -0.0003 & -0.0081 & 0.0005 & $-0.0021^{* *}$ \\
& $(0.0006)$ & $(-0.008)$ & $(0.0004)$ & $(0.0008)$ \\
Exposure to US robots $\times$ Small Firms & $-0.0014^{* *}$ & -0.0106 & $0.0009^{*}$ & $0.0020^{* * *}$ \\
& $(0.0006)$ & $(-0.007)$ & $(0.0005)$ & $(0.0006)$ \\
Exposure to US robots $\times$ Medium Firms & $-0.0020^{* *}$ & $-0.0218^{* *}$ & $0.0015^{* * *}$ & 0.0011 \\
& $(0.0007)$ & $(-0.0091)$ & $(0.0005)$ & $(0.0007)$ \\
Observations & & & & \\
\hline \hline
\end{tabular}

Note: The table reports coefficients of linear probability models for employment, hiring and separation probabilities and regression coefficient of a linear model for log wages. All regressions control for a female dummy, three age group dummies $(25-34,35-54$, and $>55$ years old), and two firm size dummies for small ( $<50$ employees) and medium-sized firms (50-250 employees). The baseline category for firm size are large firms. We also include quarter, year, industry and local labor market fixed effects. Standard errors are clustered at the state level and included in parenthesis. $*, * *$ and $* * *$ denote statistical significance at the $10 \%, 5 \%$ and $1 \%$ level respectively. 
Table 6: Effects of Robots by Industry

\begin{tabular}{|c|c|c|c|c|}
\hline & $\begin{array}{c}(1) \\
\text { Employment }\end{array}$ & $\begin{array}{c}(2) \\
\text { Log Wages }\end{array}$ & $\begin{array}{c}(3) \\
\text { Separation }\end{array}$ & $\begin{array}{c}(4) \\
\text { Hiring }\end{array}$ \\
\hline Exposure to US Robots & $\begin{array}{c}0.674^{* * *} \\
(0.187)\end{array}$ & $\begin{array}{c}9.360^{* *} \\
(3.718)\end{array}$ & $\begin{array}{c}-0.373^{* *} \\
(0.146)\end{array}$ & $\begin{array}{c}0.796^{* * *} \\
(0.108)\end{array}$ \\
\hline Exposure to US Robots $\times$ Automotive & $\begin{array}{c}-0.690^{* * *} \\
(0.185)\end{array}$ & $\begin{array}{c}-9.595^{* *} \\
(3.708)\end{array}$ & $\begin{array}{c}0.391^{* *} \\
(0.145)\end{array}$ & $\begin{array}{c}-0.776^{* * *} \\
(0.108)\end{array}$ \\
\hline Exposure to US Robots $\times$ Basic Metals & $\begin{array}{l}-0.189 \\
(0.294)\end{array}$ & $\begin{array}{l}-2.927 \\
(4.774)\end{array}$ & $\begin{array}{l}0.0203 \\
(0.202)\end{array}$ & $\begin{array}{c}-0.954^{* * *} \\
(0.220)\end{array}$ \\
\hline Exposure to US Robots $\times$ Construction & $\begin{array}{l}1.637^{* *} \\
(0.633)\end{array}$ & $\begin{array}{l}26.27^{* *} \\
(9.748)\end{array}$ & $\begin{array}{l}-1.203^{*} \\
(0.649)\end{array}$ & $\begin{array}{l}1.759 * * \\
(0.679)\end{array}$ \\
\hline $\begin{array}{l}\text { Exposure to US Robots } \times \text { Education } \\
\text { and R\&D }\end{array}$ & $\begin{array}{l}0.702^{*} \\
(0.344)\end{array}$ & $\begin{array}{c}17.76^{* * *} \\
(5.099)\end{array}$ & $\begin{array}{c}-0.680^{* *} \\
(0.261)\end{array}$ & $\begin{array}{c}0.820 \\
(0.518)\end{array}$ \\
\hline $\begin{array}{l}\text { Exposure to US Robots } \times \text { Electricity, } \\
\text { Gas and Water Supply }\end{array}$ & $\begin{array}{l}-0.292 \\
(4.440)\end{array}$ & $\begin{array}{l}-48.76 \\
(72.93)\end{array}$ & $\begin{array}{c}1.457 \\
(3.790)\end{array}$ & $\begin{array}{l}-1.796 \\
(7.782)\end{array}$ \\
\hline Exposure to US Robots $\times$ Electronics & $\begin{array}{c}-0.692^{* * *} \\
(0.186)\end{array}$ & $\begin{array}{c}-9.625^{* *} \\
(3.747)\end{array}$ & $\begin{array}{c}0.394^{* * *} \\
(0.142)\end{array}$ & $\begin{array}{c}-0.760 * * * \\
(0.114)\end{array}$ \\
\hline $\begin{array}{l}\text { Exposure to US Robots } \times \text { Food and } \\
\text { Beverages }\end{array}$ & $\begin{array}{c}-0.674^{* * *} \\
(0.182)\end{array}$ & $\begin{array}{c}-9.414^{* *} \\
(3.677)\end{array}$ & $\begin{array}{c}0.375^{* *} \\
(0.142)\end{array}$ & $\begin{array}{c}-0.790 * * * \\
(0.103)\end{array}$ \\
\hline $\begin{array}{l}\text { Exposure to US Robots } \times \text { Glass and } \\
\text { Ceramics }\end{array}$ & $\begin{array}{l}-1.408^{*} \\
(0.758)\end{array}$ & $\begin{array}{l}-32.49 \\
(20.53)\end{array}$ & $\begin{array}{c}0.877 \\
(0.558)\end{array}$ & $\begin{array}{l}-0.170 \\
(0.555)\end{array}$ \\
\hline $\begin{array}{l}\text { Exposure to US robots } \times \text { Metal } \\
\text { Machinery }\end{array}$ & $\begin{array}{l}-0.381 \\
(0.281)\end{array}$ & $\begin{array}{l}-4.998 \\
(4.965)\end{array}$ & $\begin{array}{c}0.155 \\
(0.228)\end{array}$ & $\begin{array}{c}-0.701^{* * * *} \\
(0.152)\end{array}$ \\
\hline $\begin{array}{l}\text { Exposure to US Robots } \times \text { Metal } \\
\text { Products }\end{array}$ & $\begin{array}{c}-0.594^{* * *} \\
(0.182)\end{array}$ & $\begin{array}{l}-8.221^{* *} \\
(3.664)\end{array}$ & $\begin{array}{c}0.312^{* *} \\
(0.143)\end{array}$ & $\begin{array}{c}-0.797^{* * * *} \\
(0.103)\end{array}$ \\
\hline $\begin{array}{l}\text { Exposure to US Robots } \times \text { Mining and } \\
\text { Quarrying }\end{array}$ & $\begin{array}{l}-2.505 \\
(1.472)\end{array}$ & $\begin{array}{l}-38.00^{*} \\
(20.08)\end{array}$ & $\begin{array}{c}2.068^{* *} \\
(0.967)\end{array}$ & $\begin{array}{c}0.627 \\
(1.567)\end{array}$ \\
\hline
\end{tabular}


Table 6: Effects of Robots by Industry (continued)

\begin{tabular}{|c|c|c|c|c|}
\hline & $\begin{array}{c}(1) \\
\text { Employment }\end{array}$ & $\begin{array}{c}(2) \\
\text { Log Wages }\end{array}$ & $\begin{array}{c}(3) \\
\text { Separation }\end{array}$ & $\begin{array}{c}(4) \\
\text { Hiring }\end{array}$ \\
\hline $\begin{array}{l}\text { Exposure to US Robots } \times \text { Other } \\
\text { Vehicles }\end{array}$ & $\begin{array}{c}22.09 \\
(19.43)\end{array}$ & $\begin{array}{c}316.7 \\
(290.1)\end{array}$ & $\begin{array}{l}-20.72 \\
(18.75)\end{array}$ & $\begin{array}{l}-5.379 \\
(8.026)\end{array}$ \\
\hline $\begin{array}{l}\text { Exposure to US Robots } \times \text { Other } \\
\text { Manufacturing }\end{array}$ & $\begin{array}{c}-0.676^{* * *} \\
(0.187)\end{array}$ & $\begin{array}{c}-9.376^{* *} \\
(3.718)\end{array}$ & $\begin{array}{c}0.374^{* *} \\
(0.146)\end{array}$ & $\begin{array}{c}-0.797^{* * *} \\
(0.108)\end{array}$ \\
\hline $\begin{array}{l}\text { Exposure to US Robots } \times \text { Other } \\
\text { Non-Manufacturing }\end{array}$ & $\begin{array}{c}-0.999 * * * \\
(0.272)\end{array}$ & $\begin{array}{c}-14.41^{* *} \\
(5.196)\end{array}$ & $\begin{array}{c}0.553^{* *} \\
(0.201)\end{array}$ & $\begin{array}{c}-1.343^{* * *} \\
(0.321)\end{array}$ \\
\hline Exposure to US Robots $\times$ Paper & $\begin{array}{c}0.870 \\
(0.756)\end{array}$ & $\begin{array}{c}13.19 \\
(10.46)\end{array}$ & $\begin{array}{l}-0.739 \\
(0.570)\end{array}$ & $\begin{array}{c}-1.426^{* *} \\
(0.691)\end{array}$ \\
\hline $\begin{array}{l}\text { Exposure to US Robots } \times \text { Plastic } \\
\text { and Chemical }\end{array}$ & $\begin{array}{c}-0.690 * * * \\
(0.191)\end{array}$ & $\begin{array}{c}-9.651^{* *} \\
(3.742)\end{array}$ & $\begin{array}{c}0.384^{* *} \\
(0.149)\end{array}$ & $\begin{array}{c}-0.809^{* * *} \\
(0.115)\end{array}$ \\
\hline Exposure to US Robots $\times$ Textiles & $\begin{array}{c}6.001 \\
(3.608)\end{array}$ & $\begin{array}{l}87.13^{*} \\
(45.38)\end{array}$ & $\begin{array}{l}-3.096 \\
(2.245)\end{array}$ & $\begin{array}{c}5.093 \\
(6.093)\end{array}$ \\
\hline $\begin{array}{l}\text { Exposure to US Robots } \times \text { Wood } \\
\text { and Furniture }\end{array}$ & $\begin{array}{l}-1.263 \\
(3.836)\end{array}$ & $\begin{array}{l}-35.41 \\
(53.03)\end{array}$ & $\begin{array}{c}2.691 \\
(3.017)\end{array}$ & $\begin{array}{c}10.88^{* * *} \\
(2.217)\end{array}$ \\
\hline No. Observations & $226,450,548$ & $226,450,540$ & $172,462,095$ & $53,988,453$ \\
\hline
\end{tabular}

Note: The table reports coefficients of linear probability models for employment, hiring and separation probabilities and regression coefficient of a linear model for log wages. All regressions control for a female dummy, three age group dummies (25-34, 35-54, and $>55$ years old), and two firm size dummies for small (<50 employees) and medium-sized firms (50-250 employees). The industry baseline category is Agriculture. We also include quarter, year, industry and local labor market fixed effects. Standard errors are clustered at the state level and included in parenthesis. ${ }^{*}, * *$ and $* * *$ denote statistical significance at the $10 \%, 5 \%$ and $1 \%$ level respectively. 
Table 7: Effect of Robots in Local Labor Markets: IV Estimates

\begin{tabular}{lcccc}
\hline \hline & $(1)$ & $(2)$ & $(3)$ & $(4)$ \\
& Employment & Log Wages & Separation & Hiring \\
\hline \multirow{3}{*}{$\begin{array}{l}\text { Instrumented Exposure to US } \\
\text { Robots }\end{array}$} & $-0.0009^{*}$ & -0.0115 & $0.0009^{* *}$ & -0.0008 \\
& $(0.0004)$ & $(0.0066)$ & $(0.0003)$ & $(0.0008)$ \\
& \multicolumn{4}{c}{ Panel A. 2SLS Estimates } \\
Exposure to EURO Robots & $3.6314^{* * *}$ & $3.6314^{* * *}$ & $3.6236^{* * *}$ & $3.6635^{* * *}$ \\
\cline { 2 - 5 } & $(0.0514)$ & $(0.0514)$ & $(0.0498)$ & $(0.0638)$ \\
First-stage F-statistic & $1.26 \mathrm{E}+08$ & $1.26 \mathrm{E}+08$ & $9.52 \mathrm{E}+07$ & $3.13 \mathrm{E}+07$ \\
Adj R-squared & 0.9809 & 0.9809 & 0.9807 & 0.9816 \\
& & & & \\
No. Observations & $226,450,548$ & $226,450,540$ & $172,462,095$ & $53,988,453$ \\
\hline \hline
\end{tabular}

Note: The table reports the IV estimates of the effect of exposure to US robots on employment, hiring and separation probabilities and on log wages. We use the exposure to EURO robots as instrument. All regressions control for a female dummy, three age group dummies $(25-34,35-54$, and $>55$ years old), and two firm size dummies for small (<50 employees) and medium-sized firms(50-250 employees). We include quarter, year, industry and local labor market fixed effects. We also report the first-stage coefficients and its F-statistic in all specifications. Standard errors are clustered at the state level and included in parenthesis. ${ }^{*},{ }^{* *}$ and ${ }^{* * *}$ denote statistical significance at the $10 \%$, $5 \%$ and $1 \%$ level respectively. 
Table 8: Effect of Robots in Local Labor Markets or States with Higher Informality

\begin{tabular}{|c|c|c|c|c|}
\hline & $\begin{array}{c}(1) \\
\text { Employment }\end{array}$ & $\begin{array}{c}(2) \\
\text { Log Wages }\end{array}$ & $\begin{array}{c}(3) \\
\text { Separation }\end{array}$ & $\begin{array}{c}(4) \\
\text { Hiring }\end{array}$ \\
\hline & \multicolumn{4}{|c|}{ Panel A. Informality at the LLM level } \\
\hline Exposure to US Robots & $\begin{array}{c}-0.0014^{* *} \\
(0.0006)\end{array}$ & $\begin{array}{c}-0.0208^{* *} \\
(0.0081)\end{array}$ & $\begin{array}{c}0.0014^{* *} \\
(0.0006)\end{array}$ & $\begin{array}{c}-0.0011^{* *} \\
(0.0004)\end{array}$ \\
\hline Three-year Lag Informality & $\begin{array}{c}0.0188^{* * *} \\
(0.0010)\end{array}$ & $\begin{array}{c}0.254^{* * *} \\
(0.0145)\end{array}$ & $\begin{array}{c}-0.0188^{* * *} \\
(0.0010)\end{array}$ & $\begin{array}{c}0.0188^{* * * *} \\
(0.0010)\end{array}$ \\
\hline $\begin{array}{l}\text { Exposure to US Robots } \times \\
\text { Three-year Lag Informality }\end{array}$ & $\begin{array}{l}0.00026^{*} \\
(0.00001)\end{array}$ & $\begin{array}{l}0.00041^{* *} \\
(0.00017)\end{array}$ & $\begin{array}{l}0.00057^{*} \\
(0.00001)\end{array}$ & $\begin{array}{r}0.00003^{* *} \\
(0.00001)\end{array}$ \\
\hline
\end{tabular}

Note: The table reports coefficients of linear probability models for employment, hiring and separation probabilities and regression coefficient of a linear model for log wages. All regressions control for a female dummy, three age group dummies (25-34, 35-54, and $>55$ years old $)$, and two firm size dummies for small $(<50$ employees $)$ and medium -sized firms(50-250 employees). The industry baseline category is Agriculture. We also include quarter, year, industry and local labor market fixed effects. Standard errors are clustered at the state level and included in parenthesis. $*$, ** and *** denote statistical significance at the $10 \%, 5 \%$ and $1 \%$ level respectively. 
Table 9: Effects of Robots for Sectors in Local Labor Markets with Higher US Exports and Imports

\begin{tabular}{lcccc}
\hline \hline & $\begin{array}{c}(1) \\
\text { Employment }\end{array}$ & $\begin{array}{c}(2) \\
\text { Log Wage }\end{array}$ & $\begin{array}{c}(3) \\
\text { Separation }\end{array}$ & $\begin{array}{c}(4) \\
\text { Hiring }\end{array}$ \\
\hline Exposure to US Robots & -0.0001 & 0.0011 & 0.0003 & -0.0003 \\
& $(0.0004)$ & $(-0.0067)$ & $(0.0003)$ & $(0.0003)$ \\
Three-year Lag Exports per GDP & 0.0489 & 0.8490 & -0.0259 & $0.0397^{*}$ \\
& $(0.0425)$ & $(-0.5870)$ & $(0.0327)$ & $(0.0221)$ \\
& $-0.0099^{* *}$ & $-0.129^{* * *}$ & $0.0084^{* *}$ & 0.0047 \\
Exposure to US Robots $\times$ Three- & $(0.0045)$ & $(-0.0685)$ & $(0.0038)$ & $(0.0040)$ \\
year Lag Exports & $-0.1160^{* * *}$ & $-1.721^{* * *}$ & $0.0712^{* * *}$ & $-0.1730^{* *}$ \\
& $(0.0211)$ & $(-0.3560)$ & $(0.0097)$ & $(0.0651)$ \\
Three-year Lag Imports per GDP & & & & -0.0011 \\
& $-0.0039^{*}$ & $-0.0432^{* * *}$ & $0.0033^{*}$ & \\
Exposure to US Robots $\times$ Three- & $(0.0022)$ & $(-0.0332)$ & $(0.0017)$ & $(0.0008)$ \\
year Lag Imports & & & & \\
& $226,450,548$ & $226,450,547$ & $172,462,095$ & $53,988,453$ \\
\hline
\end{tabular}

Note: The table reports coefficients of linear probability models for employment, hiring and separation probabilities and regression coefficient of a linear model for log wages. All regressions control for a female dummy, three age group dummies (25-34, 35-54, and >55 years old), and two firm size dummies for small ( $<50$ employees) and medium-sized firms (50-250 employees). We also include quarter, year, industry and local labor market fixed effects. Standard errors are clustered at the state level and included in parenthesis. *, ** and $* * *$ denote statistical significance at the $10 \%, 5 \%$ and $1 \%$ level respectively. 
Exposure to US robots (2011)

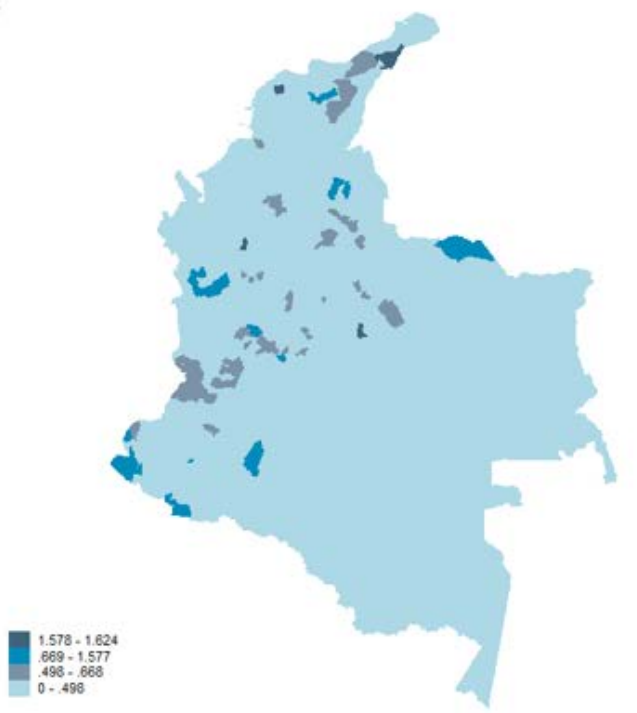

Exposure to US robots (2016)

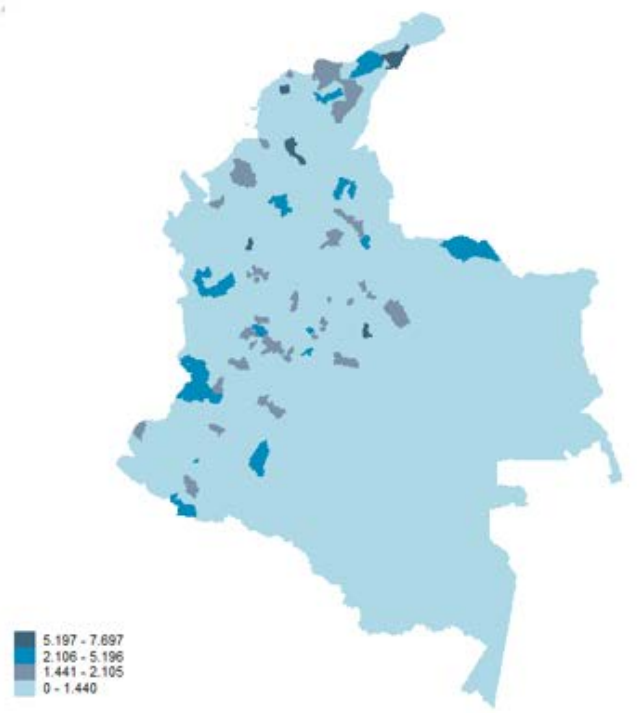

Figure 1: Exports and Imports per GDP by Local Labor Market

Exports to GDP ratio (2011)

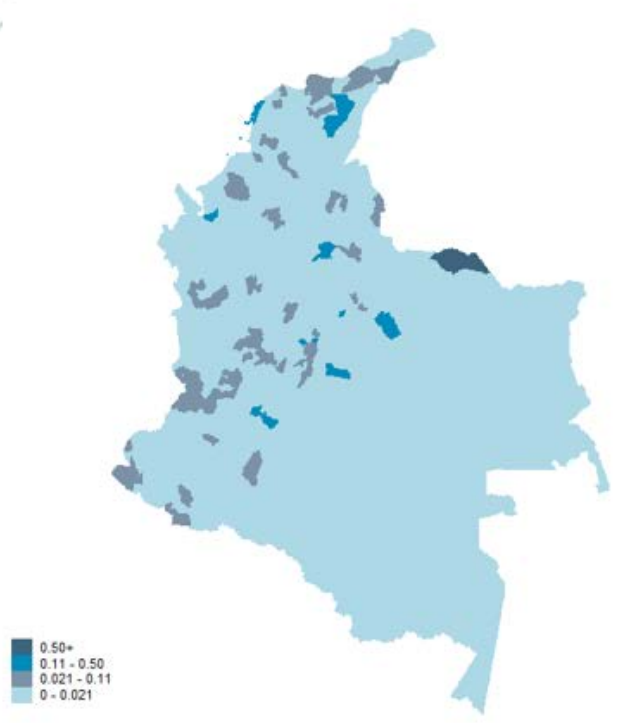

Imports to GDP ratio (2011)

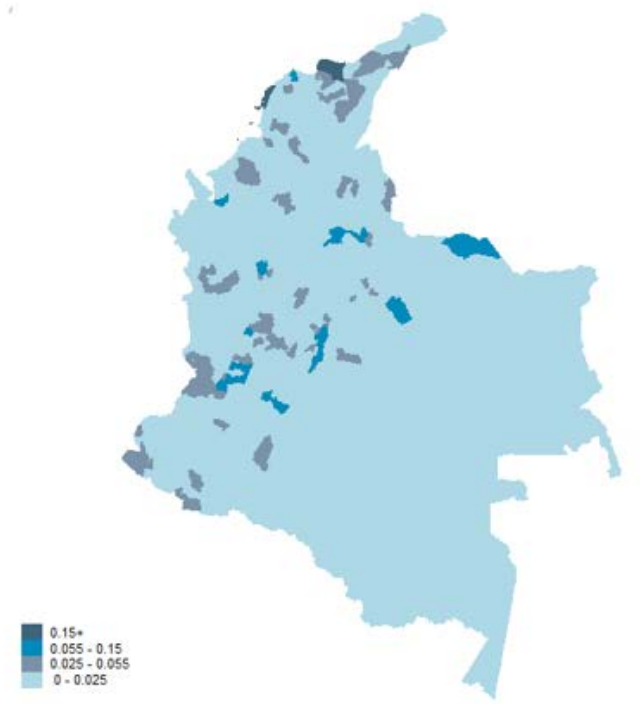

Figure 2: Weighted Exports and Imports by Local Labor Market 


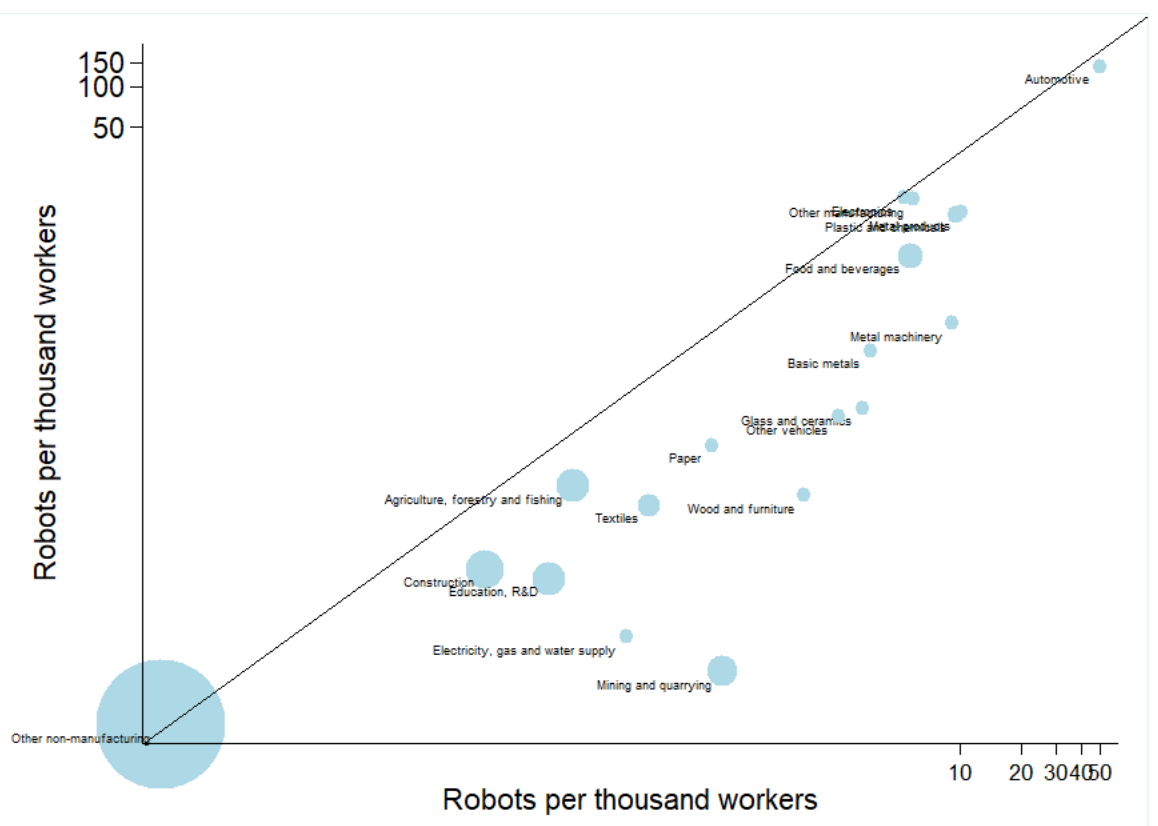

Figure 3: US and EURO Robots by Industry (first-stage) 


\section{A Appendix: NOT FOR PUBLICATION}

Table 1.A: Effects of US Robots on Employment, Separations and

\begin{tabular}{cccc}
\multicolumn{4}{c}{ Hires, Logit Model } \\
\hline \hline & $(1)$ & $(2)$ & $(3)$ \\
Exposure to US robots & Employment & Separation & Hiring \\
\cline { 2 - 4 } & $-0.0018^{* * *}$ & $0.0015^{* * *}$ & -0.0007 \\
& $(0.0003)$ & $(0.0002)$ & $(0.0006)$
\end{tabular}

No. Observations $\quad 226,450,548 \quad 172,462,095 \quad 53,988,453$

Note: The table reports the average marginal effects of a logit model for employment, hiring and separation probabilities. All regressions control for a female dummy, three age group dummies $(25-34,35-54$, and $>55$ years old) and two firm size dummies for small $(<50$ employees) and medium-sized firms (50-250 employees). We include quarter, year, industry and local labor market fixed effects. Standard errors are clustered at the state level and included in parenthesis. ${ }^{*},{ }^{* *}$ and $* * *$ denote statistical significance at the $10 \%, 5 \%$ and $1 \%$ level respectively. 